\title{
Asociación de la adicción a Internet con la ansiedad social y la falta de habilidades sociales en adolescentes españoles
}

\section{Association of Internet addiction with social anxiety and lack of social skills in spanish adolescents}

\author{
Estefanía Torrente \\ José Antonio Piqueras* \\ Mireia Orgilés \\ José Pedro Espada \\ Departamento de Psicología de la Salud, Universidad Miguel Hernández de Elche, Elche, España.
}

(Rec: 07 enero 2014 / Acept: 10 noviembre 2014)

\begin{abstract}
Resumen
El objetivo de este trabajo es analizar la relación de la adicción a Internet con la ansiedad social y las dificultades en habilidades sociales en una muestra de 446 adolescentes españoles entre 12 y 16 años. Los resultados muestran que los adolescentes con puntuaciones elevadas en adicción a Internet presentan mayores niveles de ansiedad social y de dificultades en las habilidades sociales. Además, la adicción intrapersonal se asoció positiva y significativamente tanto con el grado de ansiedad social como con la falta de asertividad. Por su parte, la adicción interpersonal lo hizo en mayor medida con la ansiedad social. Los datos obtenidos en este estudio pueden ser de ayuda de cara al diseño de programas de prevención para un uso saludable de la conexión a Internet a nivel escolar y familiar.

Palabras clave: adicción a Internet, ansiedad social, habilidades sociales, relaciones interpersonales y adolescentes.
\end{abstract}

\begin{abstract}
The aim of this study is to analyse the relationship between Internet addiction andsocial anxiety and social skills difficulties in a sample consisting of 446 Spanish adolescents between 12 and 16 years old.Our results show thatadolescents with high scores in problematic use of the Internetpresent higher scores in social anxiety and social skills difficulties. Furthermore, the intrapersonal addiction showed a positive significant association both with the degree of social anxiety and with lack of assertiveness. On the other hand, the interpersonal addiction did more with social anxiety. Data from this study can help to design and implement prevention programs for a healthy use of the Internet at school and inhome settings.

Keywords: internet addiction, social anxiety, social skills, interpersonal relationships, adolescents.
\end{abstract}

\footnotetext{
Correspondencia:

José A. Piqueras, Departamento de Psicología de la Salud, Universidad Miguel Hernández de Elche, Edificio Altamira. Avda. de la Universidad s/n, Edf. Altamira. 03202 Elche (Alicante). E-mail: jpiqueras@umh.es

Special thanks are due to Chantelle Jean Doughty for her assistance in the translation of this paper and to Úrsula E. Oberst and Xavier Carbonell (Universitat Ramón Llull, Barcelona) for their permission to use the Internet-Related Experiences Questionnaire (Cuestionario de Experiencias Relacionadas con Internet, CERI).
} 


\section{Introduction}

Internet addiction is classified within the behavioural addictions, whichshows common characteristics with other types of addictions, such as loss of control, the appearance of abstinence syndrome, a strong psychological dependence, interference in daily life activities, and loss of interest in other activities (Echeburúa \& Amor, 2001). Although the expression Internet addiction is constantly alluded to, there is not a consensus regarding this phenomenon in the scientific community and various terms can be found in scientific literature such as "Internet Addiction" (Young, 1998), "Computer Addiction" (Charlton, 2002), "Compulsive Internet Use" (Greenfield, 1999; Meerker, Van den Eijden \& Garretsen, 2006), "Pathological Internet Use" (Davis, 2001), "Problematic Internet Use" (Aboujaoude, Koran \& Serpe, 2006; Caplan, 2003), "Unregulated Internet Usage" (La Rose, Lin \& Eastin, 2003). In any case, they tend to be referring to the same phenomenon, even with different terms.

However, Internet addiction, the same as the majority of behavioural addictions (the only exception being pathological gambling), are not currently gathered in any of the most used classifying systems, such as the Diagnostic and Statistical Manual of Mental Disorders, Revised Text (DSM-IV-TR; American Psychiatric Association, 2000) or the Tenth Revision of the International Classification of Diseases (ICD-10; World Health Organization, 1992), and are not recognised as mental disorders. Nevertheless, the recent fifth edition of the DSM (DSM-5, APA, 2013) suggests in section III, Internet gaming disorder, encouraging investigation and clinical experience to determine its condition (Berner \&Santander, 2012). In fact, the Internet is one of the areas of most interest in the context of nonsubstance related behavioural addictions (Sim, Gentile, Bricolo, Serpelloni \& Gulamoydeeen, 2013).

The potential, inappropriate and excessive use of certain applications has given way to some concern about the psychological and behavioural impact that the Internet could have on individuals (Blaszczynski, 2006). On one hand, various investigations have found a relationship between Internet addiction and variables such as affectivity, low self-esteem, poor interpersonal relationships, dysfunctional family history, tendency to isolation and reality evasion, among other characteristics (e.g., Casas, Ruiz-Olivares, \& Ortega-Ruiz, 2013; Cruzado, Matos \& Kendall, 2006). Another group of variables that have been associated with the addictive use of the Internet are greater social anxiety and more difficulties regarding social skills (e.g., Echeburúa,
Labrador \& Becoña, 2009; Herrera, Pacheco, Palomar \& Zavala, 2010; Liu \& Kuo, 2007).

Nevertheless, there is another research approach that emphasises the positive role that some of the latest Internet developments, such as those known as social networks (Tuenti, Twitter, Facebook...) on young people. Thus, social networks are social spaces created for interpersonal relationships, with the aim to create a space in which registered people can communicate, share opinions, emotions or experiences and, overall, interact (Echeburúa \& Requesens, 2012). Among young people, the Internet is a vehicle for social relationships and the mean to develop relationships that are established on those networks. According to the European study "EU Kids Online", in Spain more than $79 \%$ of young people have a profile on a social network (Garmendia, Garitaonandia, Martínez \& Casado, 2011). In this sense, some experts state that new technologies can promote social relationships due to its universal nature (Civille, 1995; Katz \& Aspden, 1997). Facing this optimistic opinion, other researchers state the possibility of the use of these technologies generates isolation (Nie \& Erbring, 2000; Stoll, 1995) or intensifies phenomenon such as solitude or depression (Kraut et al., 1998). In fact, some of the most recent studies on social networks show that the number of online contacts correlates with a greater subjective feeling of well-being in young people users of the Internet (Kim and Lee, 2011). Furthermore, this fact can increase the probabilities of possible Internet addiction (Echeburúa \& Corral, 2010).

Apart from the potential negative and positive effects of the inappropriate use of the Internet, a relatively new aspect is the consideration of Internet addiction from both intrapersonal and interpersonal dimensions (Carbonell, Graner, Beranuy \& Chamarro, 2009). From this point of view, it is possible to differentiate an intrapersonal addiction, that includes aspects such as tolerance increase, negative effects, reduction of activities, loss of control, avoidance of other activities, and the urgency or need to be online; and an interpersonal addiction, which covers the interpersonal relationships on the Internet, as well as the need to establish friendships online, and the ease in which they can establish online relationships (Carbonell et al., 2009). Thus, a recent study points out that it is interpersonal Internet addiction what better explains the addiction versus the intrapersonal factor. Consequently, the interpersonal dimension is the most related aspect with the Internet addiction (Casas et al., 2013). So that everything referred to up to this point, adolescence deserves special attention regarding their relationships 
with new technologies. Thus, it has been considered as a risk group due to the characteristics of this developmental stage: tendency to look for the cause of their problems in others, little life experience, difficulty to recognise subtle addictions, and the sensation of normality regarding risky behaviours (Castellana \& Lladó, 1999). According to the study carried out by the Pfizer Foundation (2009), 98\% of young Spanish people from 11 to 20 years old are users of the Internet and it is, there fore, an obvious reality: the high amount of use of the new technologies among adolescents and young people (Johansson \& Götestam, 2004; MuñozRivas, Navarro \& Ortega, 2003).

According with the above considerations, our research questions are as follows: is Internet addiction really associated to a greater degree of social anxiety and greater deficiencies in social skills difficulties?; and in which way are they related to intrapersonal and interpersonal addictions?. Consequently, the aim of this study is to find out if Internet addiction in general, and its interpersonal and intrapersonal dimensions, are related to social anxiety and social skills difficulties in Spanish adolescence population.

\section{Method}

\section{Participants}

The sample consisted of 446 students ( 222 boys and 224 girls) between 12 and 16 years old with an average age of $14.15(S D=1.18)$, attending two public education centres in the Province of Alicante (Spain). The sampling method was incidental or conveniences ampling.

The Chi-square test to verify the homogeneity of the frequency distribution indicates that there was not interdependence between sex and age, neither between sex and nationality nor between sex and socio-economic level $\left(x^{2}=\right.$ $4.50 ; p=.19 ; x^{2}=33.09 ; p=0.46 ; x^{2}=1.39 ; p=.49$; respectively). Consequently, the distribution can be considered homogeneous.

\section{Instruments}

The following questionnaires and inventories, with their corresponding descriptions, were used as instruments.

- Brief Form of the Social Phobia and Anxiety Inventory for Adolescents (SPAI-B; García-López, Hidalgo, Beidel, Olivares \& Turner, 2008). It assesses the behavioural, psychophysiological, and cognitive aspects of social anxiety with 16 items using the 5-point Likert scale format, that produce one global dimension. The scale has shown excellent psychometric properties in adolescents (García-López et al., 2008) and in young Spanish adults (Piqueras, Espinosa-Fernández, García-López \& Beidel, 2012).

- Questionnaire about Interpersonal Difficulties for Adolescents (Cuestionario de Evaluación de Dificultades Interpersonales en la Adolescencia, CEDIA; Ingles, Méndez \& Hidalgo, 2000). The questionnaire consists of a self-report measure intended to detect the interpersonal anxiety or interpersonal difficulties in adolescents between 12 and 18 years old. It is composed of 39 items distributed in 5 factors: Assertiveness, Heterosexual Relationships, Close Relationships, Public Speaking and Family Relationships. The questions gather samples of a wide range of interpersonal relationships with people of different ages, gender, levels of authority and intimacy in several contexts: family, school, friends, opposite sex peers, and situations in the street, shops and public buildings. The adolescent rates his/her degree of difficulty on a 5 point Likert scale $(0=$ no difficulty; $4=$ maximum difficulty). The CEDIA shows adequate psychometric properties, high reliability and a dimensional structure (construct validity).

- Internet-related Experiences Questionnaire(Cuestionario de Experiencias Relacionadas con Internet, CERI; Carbonell et al., 2009). It is an adaptation of the questionnaire created by De Gracia et al. (2002), and is based on the DSM-IV criterion for substance abuse and pathological gambling. It is a 10 Likert type items questionnaire with 4 answer options ( 1 to 4 ) distributed in two factors: Intrapersonal Conflicts, that includes items referring to tolerance increase, negative effects, activity reduction, loss of control, avoidance of other activities and the urgency or need to be online and; Interpersonal Conflicts, that gathers information about interpersonal relationships over the Internet, the need to establish online friendships and the ease in which they can establish these relationships online (Carbonell et al., 2009). This questionnaire has recently been validated in the Spanish adolescent population (Casas et al., 2013), showing a factorial structure similar to the one found in adult population and internal consistence values of .79 for the total score, .72 for the Intrapersonal factor and .64 for the Interpersonal, although it indicated some differences in the factor structure of the items. In the current study we used the factorial solution found by Casas et al. (2013). 


\section{Procedure}

After requesting the corresponding authorizations to the school headmasters, the participants parents/tutors and themselves were informed of the characteristics and aims of the research, ensuring the confidential, anonymous, and voluntary nature of the survey. Once the informed consent was obtained, the collective administration (in the classroom) of the instruments was applied by an online survey application. During the group application in the computer rooms, there was a psychologist supervising and solving questions.

A transversal descriptive study was carried out, in which the effect of the independent variables considered (social anxiety level and social skills difficulties) on the dependent (Internet addiction) was observed. It consists of an ex post facto investigation, as the effects of events already taken place were observed.

\section{Data Analysis}

Three types of analysis were carried out to study the relationship between Internet addiction and social anxiety and social skills.

Firstly, Student's $t$ tests for independent samples were used with the aim to verify if significant differences exist between the group of adolescents with high scores in Internet addiction and the group with normal scores in Internet addiction in the variables social anxiety and difficulties in social skills. The statistical significance level required in all the tests has been $p<.05$.The Cohen's $d$ (typified mean difference) (Cohen, 1988) was included. Itallows the estimation of the magnitude or the effect size of the differences found. Its interpretation is as follows: small $(0.20-0.49)$, medium $(0.50-0.79)$ and large effect size $(\geq 0.80)$.

To classify the sample into the two groups, the average score in the Total CERI was used. Thus, the group with high scores in Internet addiction consisted of those subjects that presented a score the same or more than one standard deviation above the mean, while the rest made up the group without Internet addiction (see Table 1).

Secondly, bivariate correlation analyses were carried out to determine the association between variables in the total sample. The correlation size between the variables was estimated following Cohen's criterion (1988). Thus, a small size of the association size is considered when it is less or the same as 0.10 , medium when it is around 0.30 and large when it is the same or more than 0.50 (Cohen, 1988; Lipsey \& Wilson, 2001).

Afterward, with the aim to establish the predictive value of the variables considered in the study, hierarchical multiple regression analyses were carried out, using the two dimensions and the total CERI score as criterion variables. We introduced the socio-demographic variables (sex, age and

Table 1.Descriptive data of the sample.

\begin{tabular}{lcc}
\hline Instruments & $\mathrm{M}$ & $\mathrm{SD}$ \\
\hline CERI Total & 19.10 & 5.71 \\
CERI-Interpersonal Conflicts & 10.73 & 3.30 \\
CERI-Intrapersonal Conflicts & 8.37 & 2.97 \\
SPAI-B & 16.23 & 11.65 \\
CEDIA (assertiveness) & 18.03 & 12.02 \\
CEDIA (heterosexual relationships) & 12.47 & 7.11 \\
CEDIA (public speaking) & 5.71 & 4.47 \\
CEDIA (family relationships) & 2.33 & 3.16 \\
CEDIA (close relationships) & 2.79 & 3.47 \\
CEDIA Total & 41.34 & 24.51 \\
\hline
\end{tabular}

Note: $M$-Mean; SD-Standard Deviation; CERI-Internet-Related Experiences Questionnaire; CEDIA-Questionnaire about Interpersonal Difficulties for Adolescents; SPAI-B-Brief Form of the Social Phobia and Anxiety Inventory for Adolescents. 
socioeconomic level) in the first block, the social anxiety score in the second block, and the social skills difficulties in the third one. In this way the contribution of each one of the studied variables can be examined (social anxiety and difficulties in social skills) due to the fact of they are introduced subsequently in the equation, as well as establishingif there is a significant increase in the criterion explained variance, each time a block of variables are introduced into the equation. In other words, with this type of analysis the aim was to establish the specific contribution of the variables of this study (social anxiety and social skills), once controlled the effect of the socio-demographic variables.

Previous to the different regression analyses, the correlations between all the predictor or independent variables were analysed, with the aim to verify that those bivariate correlations were less than .70 and, the Tolerance indicators and the Variance Inflation Factor were studied to be able to rule out the existence of multicollinearity(Tabachnick \& Fidell, 1996). No indicators of collinearity were found and on that basis a decision was taken to include both groups of variables in the same analysis: social anxiety dimension in the second step and the subscales of the CEDIA in the third block.

\section{Results}

\section{Differences in social anxiety and social skills based on Internet addiction}

The means and standard deviations of each of the variables considered in this study can be seen in Table 1 .

From the whole sample of 446 adolescents, 80 presented high scores in Internet addiction, while the rest did not (336). As can be observed in Table 2, there were significant statistic differences in all of the variables except in the CEDIA factors of Heterosexual Relationships, Public Speaking, and Family Relationships. When analysing the effect sizes, these were medium in the SPAI-B total score, the total score of the CEDIA, and in the factors of Assertiveness, Public Speaking, Family Relationships, and Close Relationships.

Table 2. Mean, standard deviation, significance test and the effect size of the variables in Internet addicts and non-addicts.

\begin{tabular}{|c|c|c|c|c|c|c|c|}
\hline & ADDICT & & NON-A & ICT & & & \\
\hline & $M$ & $S D$ & $M$ & $S D$ & $\mathrm{~T}$ & Sig. & $d$ \\
\hline SPAI-B & 20.86 & 13.41 & 15.21 & 10.99 & -3.51 & .001 & .46 \\
\hline CEDIA (assertiveness) & 22.38 & 14.62 & 17.08 & 11.17 & -0.05 & .003 & .40 \\
\hline CEDIA(heterosexual relationships) & 13.27 & 7.15 & 12.29 & 7.09 & -1.11 & .269 & - \\
\hline CEDIA (public speaking) & 6.63 & 5.44 & 5.50 & 4.21 & -1.75 & .082 & - \\
\hline CEDIA (family relationships) & 2.95 & 3.99 & 2.19 & 2.93 & -1.58 & .115 & - \\
\hline CEDIA (close relationships) & 3.75 & 4.23 & 2.58 & 3.24 & -2.31 & .023 & .31 \\
\hline CEDIA Total & 49 & 30.01 & 39.66 & 22.84 & -2.62 & .010 & .35 \\
\hline
\end{tabular}

Note: Addict: a score at or above one SD above the mean; M- Mean; SD- Standard Deviation; T- Student's t-test for two independent samples with heterogeneous variances; Sig-Statistical significance; $d$-Cohen's d to estimate the effect size of the differences. 
The only variable with a small effect size is the Heterosexual Relationships factor from the CEDIA.

\section{Correlations between Internet addiction, social anxiety, and social skills}

The results from the correlation analysis of the two CERI dimensions (intrapersonal and interpersonal conflicts) and its total score indicated that, in general, all the correlations were positive and significant $(p<.01)$ (see Table 3 ). Thus, a higher score in Internet addiction was related with a greater level on social anxiety and social skills difficulties.

Regarding the total score in the CERI, the biggest effect sizes were in the SPAI-B and the CEDIA total score and its Assertiveness subscale, being medium effect sizes. The correlation magnitudes with their subscales also have a medium effect size.

Regarding the interpersonal conflicts factor, the largest effect sizes were with SPAI-B, showing a medium effect size. The effect sizes were medium in the relation with the CEDIA total and subscales scores, with the exception of the Family Relationship factor, which is nearer to a small effect size.
Regarding the intrapersonal conflicts factor the biggest effect sizes were in the CEDIA total score and its Assertiveness subscale, being a medium effect size. The SPAI-B and the subscales of the CEDIA also have a medium effect size with the exception of the Heterosexual Relationships factor which has a small effect size.

\section{Predictive models for Internet addiction based on social anxiety and social skillsdeficit}

In Table 4 appear the results in reference to the hierarchal multiple regression analysis, in which the variables have been introduced using the total score in the CERI as criterion and each of the two subscales: Inter and Intrapersonal Conflicts.

Firstly, the contribution of the socio-demographic variables block was not significant in the models regarding the Total CERI, Interpersonal and Intrapersonal Conflicts $(p=.66, .52$ y .87, respectively). With the inclusion of the second block of the social anxiety score, there was a significant increase in the explained variance in the three models: 6,6 , and $4 \%$ $(\mathrm{p}=.001)$, respectively. With the inclusion of the CEDIA subscales in the third block, there was a significant increase in the variance in the Total CERI and in the Intrapersonal CERI: 3 and 5\%, respectively. In conclusion, the results

Table 3.Pearson'scorrelations between the CERI and its subscales and the studied variables: frequency in the use of the Internet, frequency in the use of social networks, social anxiety and social skills difficulties.

\begin{tabular}{|c|c|c|c|}
\hline & $\begin{array}{c}\text { CERI } \\
\text { Interpersonal Conflicts }\end{array}$ & $\begin{array}{c}\text { CERI } \\
\text { Intrapersonal Conflicts }\end{array}$ & $\begin{array}{l}\text { CERI } \\
\text { Total }\end{array}$ \\
\hline $\begin{array}{l}\text { Social Anxiety } \\
\text { (SPAI-B) }\end{array}$ & $.25 * *$ & $.21 * *$ & $.25 * *$ \\
\hline CEDIA Assertiveness & $.20 * *$ & $.26^{* *}$ & $.25 * *$ \\
\hline $\begin{array}{l}\text { CEDIA Heterosexual } \\
\text { Relationships }\end{array}$ & $.15^{* *}$ & $.09 *$ & $.14 * *$ \\
\hline CEDIA Public Speaking & $.20 * *$ & $.18 * *$ & $.21 * *$ \\
\hline CEDIA Familiy Relationships & $.13 * *$ & $.24 * *$ & $.20 * *$ \\
\hline CEDIA Close Relationships & $.17 * *$ & $.22 * *$ & $.21 * *$ \\
\hline CEDIA Total & $.22 * *$ & $.25 * *$ & $.26 * *$ \\
\hline
\end{tabular}

Note: CERI-Internet-Related Experiences Questionnaire; CEDIA-Questionnaire about Interpersonal Difficulty for Adolescents; SPAI-B-Brief form of the Social Phobia and Anxiety Inventory for Adolescents. ${ }^{*} p<.05 ; * * p<.01$ 
Table 4. Summary of the hierarchal regression analysis for the predictive variables of the total score of Internet addiction (CERI Total, CERI Interpersonal Conflicts y CERI Intrapersonal Conflicts).

\begin{tabular}{|c|c|c|c|c|c|c|c|c|c|c|c|c|c|c|c|c|c|}
\hline & \multirow[b]{2}{*}{ Variables } & \multicolumn{3}{|c|}{ Bloque 1} & \multicolumn{4}{|c|}{ Bloque 2} & \multicolumn{9}{|c|}{ Bloque 3} \\
\hline & & Sex & Age & FAS & Sex & Age & FAS & SPAI-B & Sex & Age & FAS & SPAI-B & $\begin{array}{c}\text { CEDIA } \\
\text { RF }\end{array}$ & $\begin{array}{c}\text { CEDIA } \\
\text { RH }\end{array}$ & $\begin{array}{c}\text { CEDIA } \\
\text { AM }\end{array}$ & $\begin{array}{c}\text { CEDIA } \\
\text { HP }\end{array}$ & $\begin{array}{c}\text { CEDIA } \\
\text { AS }\end{array}$ \\
\hline \multirow{3}{*}{ CERI Total ${ }^{1}$} & B & -0.56 & 0.17 & 0.16 & -0.08 & 0.17 & 0.26 & 0.12 & -0.44 & 0.22 & 0.28 & 0.09 & 0.09 & -0.05 & 0.14 & -0.02 & 0.05 \\
\hline & $S E B$ & 0.54 & 0.23 & 0.40 & 0.53 & 0.22 & 0.39 & 0.02 & 0.56 & 0.23 & 0.39 & 0.03 & 0.12 & 0.05 & 0.11 & 0.09 & 0.04 \\
\hline & B & -0.05 & 0.03 & 0.02 & -0.01 & 0.04 & 0.03 & $0.25^{* *}$ & -0.04 & 0.04 & 0.03 & $0.18 * *$ & 0.05 & -0.07 & 0.09 & -0.02 & 0.12 \\
\hline \multirow{3}{*}{$\begin{array}{l}\text { Interpersonal- } \\
\text { Conflicts }^{2}\end{array}$} & B & 0.35 & 0.12 & 0.17 & 0.07 & 0.12 & 0.23 & 0.07 & 0.18 & 0.12 & 0.25 & 0.05 & -0.01 & -0.01 & 0.08 & 0.02 & 0.01 \\
\hline & $S E B$ & 0.31 & 0.13 & 0.23 & 0.31 & 0.13 & 0.22 & 0.01 & 0.33 & 0.13 & 0.23 & 0.02 & 0.07 & 0.03 & 0.06 & 0.05 & 0.02 \\
\hline & $B$ & 0.05 & 0.04 & 0.03 & 0.01 & 0.04 & 0.05 & $0.25^{* *}$ & 0.03 & 0.04 & 0.05 & $0.19^{* *}$ & -0.01 & -0.01 & 0.08 & 0.03 & 0.03 \\
\hline \multirow{3}{*}{$\begin{array}{l}\text { Intrapersonal- } \\
\text { Conflicts }^{3}\end{array}$} & B & -0.22 & 0.05 & -0.01 & -0.01 & 0.05 & 0.04 & 0.05 & -0.26 & 0.09 & 0.03 & 0.03 & 0.10 & -0.05 & 0.06 & -0.05 & 0.05 \\
\hline & $S E B$ & 0.28 & 0.12 & 0.21 & 0.28 & 0.12 & 0.20 & 0.01 & 0.29 & 0.12 & 0.20 & 0.02 & 0.06 & 0.03 & 0.06 & 0.05 & 0.02 \\
\hline & $B$ & -0.04 & 0.02 & -0.01 & -0.01 & 0.02 & 0.01 & $0.21 * *$ & -0.04 & 0.04 & 0.01 & $0.14 *$ & 0.10 & -0.12 & 0.07 & -0.07 & $0.19 *$ \\
\hline
\end{tabular}

Note: CERI-Internet-Related Experiences Questionnaire; SPAI-B-Brief Form of the Social Phobia and Anxiety Inventory for Adolescents; CEDIAQuestionnaire about Interpersonal Difficulties for Adolescents. 1 CERI: $R 2=0.004$ in step 1; $\Delta R 2=0.06$ for step 2 ( $p<.01$ ); $\Delta R 2=0.03$ for step 3 ( $p$ $<.01)(F=0.53, p=.66 ; F=7.87, p=.001$ y $F=5.00, p=.001$, respectively); 2 CERI-INTER: $R 2=0.005$ for step $1 ; \Delta R 2=0.06$ for step $2(p<.01) y$ $\Delta R 2=0.01$ for step $3(p=.50)(F=0.75, p=.52 ; F=7.66, p=.001$ y $F=3.89, p=.001$, respectively $) ; 3$ CERI-INTRA: R2=0.002 for step 1; $\triangle R 2=$ 0.04 for step $2(p<.001)$ y $\Delta R 2=0.05$ for step $3(p<.001)\left(F=0.24, p=.87 ; F=5.30, p=.001\right.$ y $F=5.23, p=.001$, respectively). ${ }^{*} p<.05 ; * * p<.01$.

from the hierarchal regression analysis show that regarding the total score, the model explains $9 \%$ of the total variance explained, presenting a significant relation with the level of social anxiety $(\mathrm{d}=0.25)$. The Interpersonal Conflicts model explains $7 \%$ of the variance explained, displaying a positive relationship with social anxiety $(\mathrm{d}=0.27)$, where as the Interpersonal Conflicts explains $10 \%$ of the variance explained, displaying a positive relationship with social anxiety $(\mathrm{d}=0.19)$ and lack of assertiveness $(\mathrm{d}=0.23)$. Although the effect sizes are small, the biggest relationship appears between interpersonal addiction and social anxiety.

\section{Discussion}

The main purpose of this study was to find out whether Internet addiction was related to social anxiety and social skills difficulties in a Spanish adolescent sample. The results obtained indicate that Internet use is related tohigher scores on social anxiety and in social skills difficulties. This data is consistent with previous studies that have reported the relationship of addictive use of the Internet with higher social anxiety and more social skills difficulties (e.g., Echeburúa et al., 2009; Herrera et al., 2010; Liu et al., 2007).

Regarding to the considered socio-demographic variables (sex, age, and socioeconomic level), the results indicate that gender is not related to addictive use of the Internet (Jiménez-Albiaret et al., 2012) neither with age nor the socioeconomic level, which turns out to be consistent with the data informed by previous studies (Estévez et al., 2009; Muñoz-Rivas et al., 2003; Viñas et al., 2002).

Taking into account the above three types of analyses (the comparison between adolescents with and without high scores in Internet addiction, the correlation analysis, and the regression analysis), the association between addiction and social anxiety makes evident. A possible explanation of this phenomenon is that adolescents that suffer from these symptoms feel great discomfort in real social situations and avoid going out with other people, and so the Internet gives them the possibility to contact with others and participate in games as well as ways of communicating without needing to expose themselves face-to-face to situations that provoke anxiety (Yen, Ko, Yen, Chen, Chung \& Chen, 2008).

It is also becomes evident that the deficiency or lack of social skills scores, such as the lack of assertiveness, peer relationship difficulties and general difficulties (total score) were significantly higher in the subjects that presented higher Internet addiction scores than in the non-addictive subjects, especially in the factor that evaluates lack of assertiveness in the CEDIA. Furthermore, the regression analyses indicated that the social anxiety variable was the only one significantto predict the total score in the CERI questionnaire. All of the data are consistent with the results in previous studies. For example, Peter, Valkenburg \& Schouten (2006) reported that the introverted adolescents were more strongly motivated to communicate online, as a way of compensating 
for lacking social skills, which encourages them to provide more information about themselves to their virtual friends. These adolescents pretend to show a more adult profile on the Internet than what they really are, which is explained by their few social skills, low self-esteem levels, high social anxiety and aggression levels (Harman, Hansen, Cochran \& Lindsey, 2005).

Along the same lines, there are studies that affirm that there is an equally positive correlation between quality of the relationship with parents, quality of interpersonal relationships, social anxiety and addictive use of the Internet. Thus, the more anxiety experienced by the youngsters and the perception that their relationship with peers is less satisfactory, higher the propensity to show Internet addictionis (Liu et al., 2007). Our results are consistent with these studies due to the fact that the adolescents with compatible scores with Internet addiction showed a higher propensity to high levels of social anxiety and social skills difficulties, as well in generalas to a lack of assertiveness and difficulties in peer relationships in particular.

Regarding the differential relation with the inter and intrapersonal conflicts, not very relevant differences were found, due to the fact that the intrapersonal conflicts related significantly to the lack of assertiveness as well as to a lower degree of anxiety, whereas the interpersonal conflicts only did so to social anxiety. In other words, the difference is that intrapersonal conflicts are more related to the lack of assertiveness, and to a lesser extent to the degree of social anxiety, while the interpersonal conflicts that are generated by the abusive use of the Internet is more related to social anxiety. Unlike the study of Casas et al. (2013), that found a higher relation between low self-esteem and interpersonal addiction rather than intrapersonal, our study found a clear association between interpersonal addiction and social anxiety, but also between intrapersonal addiction and social anxiety and lack of assertiveness.

It should be noted that this study has certain methodological limitations that should be taken into consideration. Among them, the use of the CERI questionnaire only to create the two groups: addictive versus non addictive; the exclusive use ofself-report measurements; the non-inclusion of other variables that could be explaining part of the variance of addictionproblem (the predictive models explain at the most $10 \%$ of that variance, so there must be a lot of other variables not considered that should be involved) and the difference between the addicts $(\mathrm{N}=80)$ and non-addict samples $(\mathrm{N}=336)$, should be pointed out. In respect to the self-report, this is one of the most recommendable techniques to collect data on this type of psychological variables, although it can present bias in the information received from the participants, and in future studies it would be convenient to include other techniques. As regards to the issues related to the sample, future studies should try to control that the sample between addicts and non-addicts is homogenous, as well as try to control to a greater extent the variables that could affect the obtained data.

In addition, this study points to future investigation challenges in this area: i) to continue with the investigation and broaden it to longitudinal studies on the considered variables; ii) toimprove some of the methodological issues of studies such as, for example, to validate the questionnaire on Internet use and social networks; iii) to use an Internet habits and social networks questionnaire, that collects more specific and quantitative data on their use and time and; iv) to use a wider age range as well as homogeneous sample sizes.

Finally, the data obtained in this study can be useful in regards to designing prevention programs at school and at home. Since the Internet grows principally among the adolescent population, a greater amount of attention should be paid to this problem in schools and in family settings, and therefore, it would be interesting to carry out intervention programs of an educational nature to prevent possible addictive pathologies.

It is also necessary, in the future, to develop tools that encourage a good use and handling of the Internet and social networks, and design programs to use the Internet as a way to treat social anxiety problems as well as problems due to social skills deficiencies through work groups by means of an online platform.

It would be convenient to carry on investigating the presence of previous psychopathology as an underlying factor of Internet and social network addiction, assessing the types of personalities most prone to abuse the Internet and social networks, to afterwards being able to develop new tools that counteract the addiction and encourage a good use of the networks.

\section{References}

Aboujaoude, E., Koran, L. M., Gamel, N., Large, M.D. \& Serpe, R. T. (2006). Potential markers for problematic internet use: a telephone survey of 2,513 adults. CNS Spectrum, 11, 750-755.

American Psychiatric Association (2000). Manual Diagnóstico y Estadístico de los Trastornos Mentales (DSM-IV. TR). Barcelona, España: Masson.

Berner, J.E. \& Santander, J. (2012). Abuso y dependencia de internet: la epidemia y su controversia. Revista Chilena de Neuro-pediatría, 50, 181-190.

Blaszczyndki, A. (2006). Internet Use: In Search of an Addiction. International Journal of Mental Health and Addiction, 4, 7-9. 
Caplan, S.E. (2003). Preference for online social interaction: A theory of problematic Internetuse and psychosocial well-being. Comumunication Research, 30, 625-648.

Carbonell, X., Graner, C., Beranuy, M. \& Chamarro, A. (2009). Fomento del uso saludable de las tecnologías de la información y comunicación en familia y escuela. En: Echeburúa, E., Labrador, F.J. \& Becoña, E. (edts). Adicción a las nuevas tecnologías en jóvenes y adolescentes (pp. 205-219). Madrid: Pirámide.

Casas, J.A., Ruiz-Olivares, R. \& Ortega-Ruiz, R. (2013). Validation of the Internet and Social Networking Experiences Questionnaire in Spanish adolescents. International Journal of Clinical and Health Psychology, $13,40-48$.

Castellana, M. \& Lladó, M. (1999). Adolescencia y juventud: prevención y percepción del riesgo al consumo. Revista Española de Drogodependencias, 24, 118-31.

Charlton, J.P. (2002). A factor-analytic investigation of computer 'addiction' and engagement. British Journal of Psychology, 93, 329-344.

Civille, R. (1995). The internet and the poor. En: Kahin, B. y Keller, J. (edts.). Public access to the internet (pp. 175-207).Cambridge, MA: MIT Press.

Cohen, J. (1988). Statistical power analysis for the behavioral science (2nd ed.). Hillsdale, NJ, USA: Lawrence Erlbaum Associates.

Cruzado, L., Matos, L. \& Kendall, R. (2006). Adicción a Internet: Perfil clínico y epidemiológico de pacientes hospitalizados en un instituto nacional de salud mental. Revista Médica Herediana, 17, 196-205.

Davis, R.A. (2001). A cognitive-behavioral model of pathological Internet use. Computers in Human Behavior, 17, 187-195.

García-López, L.J., Hidalgo, M.D., Beidel, D.C., Olivares, J. \& Turner, S.M. (2008). Brief formof the Social Phobia and Anxiety Inventory (SPAI-B) for adolescents. European Journal of Psychological Assessment, 24, 150-156.

Garmendia, M., Garitaonandia, C., Martínez, G. \& Casado, M.A. (2011). Riesgos y seguridad en Internet: Los menores españoles en el contexto europeo. Universidad del País Vasco/Euskal Herriko Unibertsitatea, Bilbao: EU Kids Online.

De Gracia, M., Vigo, M., Fernández, M.J. \& Marcó, M. (2002). Problemas conductuales relacionados con el uso de Internet: Un estudio exploratorio. Anales de Psicología, 18, 273-292.

Greenfield, D.N. (1999). Psychological characteristics of compulsive internet use: A preliminary analysis. Cyberpsychology \& Behavior 2, 403-412.

Harman, J.P., Hansen, C.E., Cochran, M.E. \&Lindsey, C.R. (2005). Liar: Internet faking but not frequency of use effects social skills, self-esteem, social anxiety, and aggression. CyberPsychology \& Behavior, 8, 1-6.

Herrera, M.F., Pacheco, M.P., Palomar, J. \& Zavala, D. (2010). La Adicción a Facebook Relacionada con la Baja Autoestima, la Depresión y la Falta de Habilidades Sociales. Psicología Iberoamericana, 18, 6-18.

Inglés, C.J., Méndez, F.X. \& Hidalgo, M.D. (2000). Cuestionario de Evaluación de Dificultades Interpersonales en la Adolescencia. Psicothema, 21, 480- 485.

Jiménez-Albiar, M.I., Piqueras, J.A., Mateu-Martínez, O., Carballo, J.L., Orgilés, M. \& Espada, J.P. (2012). Diferencias de sexo, características de personalidad y afrontamiento en el uso de Internet, el móvil y los videojuegos en la adolescencia. Health and Addictions/Salud y Drogas, $12,61-82$.

Johansson, A. \& Götestam, K.G. (2004). Internet addiction: Characteristics of a questionnaire and prevalence in Norwegian youth (12-18 years) Scandinavian Journal of Psychology, 45, 223-229.

Katz, J. E. \& Aspden, P. (1997). A nation of strangers?. Communications of the ACM, 40, 81-86.

Kim, J. \& Lee, J. E. R. (2011). The facebook paths to happiness: Effects of the number of facebook friends and self-presentation on subjective wellbeing. Cyberpsychology, Behavior, and Social Networking, 14, 359-364.

Kraut, R., Patterson, M., Lundmark, V., Kiesler, S., Mukhopadhay, T. \& Scherlis, W. (1998). Internet paradox: A social technology that reduces social involvement and psychological well-being?. American Psychologist, 53, 1017-1031.
Echeburúa, E. \& Amor, P. J. (2001). ¿Adicción a Internet o adictos a Internet?. En: Moreno, P., Blanco, C., Páez, V. y Saiz, J. (edts).Psiquiatría e Internet. Aprendiendo a utilizar Internet (pp. 131-148). Barcelona: Ars Médica.

Echeburúa, E. \& Corral, P. (2010). Adicción a las nuevas tecnologías y a las redes sociales en jóvenes: un nuevo reto. Adicciones, 22, 91-96.

Echeburúa, E., Labrador, F.J. \& Becoña, E. (2009). Adicción a las nuevas tecnologías en adolescentes y jóvenes. Madrid: Pirámide.

Echeburúa, E. \& Requesens, A. (2012). Adicción a las redes sociales y a las nuevas tecnologíasen jóvenes y adolescentes. Guía para educadores. Madrid: Pirámide.

Estévez, L., Bayón, C., de la Cruz, J. \& Fernández-Líria, A. (2009). Uso y abuso de Internet en adolescentes. En: Echeburúa, E., Labrador, F.J. y Becoña, E. (edts). Adicción a las nuevas tecnologías (pp. 101-130). Madrid: Pirámide.

Piqueras, J.A., Espinosa-Fernández, L., García-López, L.J. \& Beidel, D.C. (2012). Validación del "Inventario de ansiedad y fobia social - forma breve" (SPAI-B) en jóvenes adultos españoles. Behavioral Psychology /Psicología Conductual, 20, 3, 505-528.

La Rose, R., Lin, C. and Eastin, M. S. (2003). Unregulated Internet usage: addiction, habit, or deficient self-regulation? Media Psychology, 5, 225-253

Lipsey, M.W. \& Wilson, D.B. (2001). Practical meta-analysis (Applied Social Research Methods Series, Vol. 49). Thousand Oaks, CA: Sage.

Liu, C.Y. \& Kuo, F.Y. (2007). A study of Internet addiction through the lens of the interpersonal theory. Cyber Psychology and Behavior, 10, 799-804.

Meerkerk, G.J., Van den Eijnden, R.J. \&Garretsen, H.F. (2006). Predicting compulsive internet use: it's all about sex!. Cyberpsychology \& Behavior, 9, 95-103.

Muñoz-Rivas, M.J., Navarro, M.E. \& Ortega, N. (2003). Patrones de uso de Internet en población universitaria española. Adicciones, 15, 137 144.

Nie, N.H. \& Erbring, L. (2000). Internet and Society: A Preliminary Report. Stanford Institute for the Quantitative Study of Society, Stanford University, and Inter Survey Inc. Recuperado desde http://www. stanford.edu/group/siqss

OMS (1992). CIE-10. Clasificación Estadística Internacional de Enfermedades y Problemas relacionados con la salud. Ginebra, OMS

Sim, T., Gentile, D.A., Bricolo, F., Serpelloni, G. \& Gulamoydeen, F. (2012). A conceptual review of research on the pathological use of computers, video games, and the internet. International Journal of Mental Health and Addiction, 10, 748-769.

Stoll, C. (1995). Silicon snake oil. New York, NY: Doubleday.

Tabachnick, B.G. \& Fidell, L.S. (1996). Using multivariate statistics (3rd ed.). New York: Harper Collins College Publisher.

Valkenburg, P.M., Peter, J. \& Schouten, A P. (2006). Friend networking sites and their relationship to adolescents social self-esteem and wellbeing. Cyberpsychology \& Behavior, 9, 585-590.

Viñas, F., Juan, J., Villar, E., Caparrós, B., Pérez, I. \& Cornella, M. (2002). Internet y psicopatología: las nuevas formas de comunicación y su relación con diferentes índices de psicopatología. Clínica y Salud, 13, 235-256.

Yen, J., Ko, C., Yen, C., Chen, S., Chung, W. \& Chen, C. (2008). Psychiatric symptoms in adolescents with Internet addiction: Comparison with substance use. Psychiatry \& Clinical Neurosciences, 62, 1-9.

Young, K. (1998). Internet Addiction: The emergence of as new clinical disorder. Cyberpsychology \& Behavior, 1, 237-244. 
